\title{
TRAJETÓRIAS DE UMA PESQUISA DE POLÍTICA DE FORMAÇÃO DOCENTE
}

Luciana Castro $^{1}$

Resumo: A formação docente é pauta nas discussões do cenário político e educacional, vista como estratégia para a promoção da qualidade do ensino. Contudo, a vivência de uma formação inicial capaz de permitir aos professores construírem uma base de conhecimentos sólidos para realizarem a tarefa de ensinar ainda é um desafio. Desse modo, a formação continuada perde a potencialidade de ser indutora de elementos reflexivos que possibilitam aos professores analisarem suas ações cotidianas, indagarem sobre suas possibilidades de intervenção, examinarem as razões do que se passa na sala de aula, o que implica no enfraquecimento de sua condição para melhorias na educação. Nesse contexto que indica a necessidade da reconfiguração do processo formativo, importante fomentar a discussão no campo de políticas de formação. Com base nesse entendimento, realizou-se uma pesquisa que buscou o diálogo com os formadores que atuaram em um dos polos do maior programa de formação continuada realizado na realidade brasileira, a saber, o Pacto Nacional pela Alfabetização na Idade Certa (PNAIC). Neste trabalho serão delineados os percursos da realização do estudo tendo em vista apresentar contribuições para o campo da pesquisa em políticas de formação de formação docente.

Palavras-chave: Política de Formação Docente; PNAIC; Melhoria das Práticas Pedagógicas.

\section{Introdução}

Passados mais de 20 anos da promulgação da Lei de Diretrizes e Bases da Educação Nacional brasileira, Lei 9.394/96, é preciso considerar que em meio ao profícuo debate no campo da Formação Docente, ainda temos lacunas significativas em torno das políticas de formação docente (GATTI; BARRETO; ANDRÉ, 2011). Sobre a formação inicial pesam as críticas referentes, principalmente, a dissociação teoria-prática, estágios fictícios (CANDAU, 2003); currículos inchados e fragmentados (GATTI, 2013) e avaliação precária. Como reflexo, legitima-se a predominância de políticas e programas voltados para a formação continuada com caráter "compensatório" das fragilidades da formação inicial.

Desse modo, na realidade brasileira, a formação continuada docente no Brasil ainda se pauta, predominantemente, em encontros que visam oferecer conteúdos e técnicas de forma prescritiva e funcional. Opera a partir de ações pontuais, isoladas e de curta duração que nada ou pouco contribuem para romper com a lógica da "educação bancária" (FREIRE, 1997) em que os conhecimentos são repassados aos docentes em desarticulação com o trabalho docente. Além disso, esse momento da formação assume um caráter individual no qual o docente é isolado de seu contexto de atuação.

De acordo com estudos bibliográficos referentes à temática, pesam ainda nas propostas de formação continuada críticas acerca da descontinuidade de políticas, falta de integração teoria-prática, princípio fundamental para o desenvolvimento profissional. Refutando essa lógica que sustenta a

\footnotetext{
${ }^{1}$ Professora da Rede Municipal de Ensino de Juiz de Fora e doutora em Educação. lu_casttro@yahoo.com.br
} 
formação continuada no contexto brasileiro, pesquisadores como Dourado (2015) e Gatti (2013; 2015) destacam que é fundamental que a vivência da formação continuada não seja o acúmulo de cursos ou técnicas, mas sim a efetiva oportunidade de construção de conhecimentos sólidos que possam oportunizar aos docentes assumirem com autonomia, novas posturas e formas de agir no contexto escolar. Para tanto, defendem a valorização da prática como ponto de partida para a mobilização de novos saberes. No campo acadêmico defende-se uma formação que busque estruturar-se na teorização da prática. Desse modo, a expectativa é que para além de se constituir na realidade brasileira como direito legal da categoria docente, a formação continuada se traduza como um momento capaz de oportunizar a vivência de uma reflexão crítica na e sobre a prática docente (GARCIA, 1999; IMBERNÓN, 2011). Com efeito, como uma real possibilidade de ser indutora de elementos reflexivos que possibilitam aos professores analisarem suas ações cotidianas, indagarem sobre suas possibilidades de intervenção, examinarem as razões do que se passa na sala de aula, o que implica no enfraquecimento de sua condição para melhorias na educação (NÓvOA, 1995, 1998; SCHÖN, 1995).

É nesse cenário que a partir do ano de 2013 (BRASIL, 2012) foi instituído pelo Ministério da Educação, no âmbito do Plano de Desenvolvimento da Educação (PDE), o Pacto Nacional pela Alfabetização na Idade Certa (PNAIC). Realizou-se como um programa organizado a partir de quatro eixos: formação continuada de professores alfabetizadores; materiais didáticos; avaliação; gestão, mobilização e controle social, tendo em vista apoiar todos os professores com atuação nos três primeiros anos da alfabetização e em turmas multisseriadas quanto ao planejamento das aulas, à definição de processo de avaliação e acompanhamento das aprendizagens das crianças do ciclo de alfabetização, à utilização dos materiais didáticos e pedagógicos ofertados pelo Ministério da Educação (BRASIL, 2012a). Nesse trabalho a formação continuada terá visibilidade tendo em vista desvelar parâmetros para a revisão e implementação de novas propostas formativas para a docência.

\section{A Formação Continuada pelo PNAIC: itinerários de uma pesquisa}

O PNAIC foi realizado em nível nacional até o ano de $2016^{2}$, por meio de uma rede articulada entre governo federal, as Instituições de Ensino Superior (IES) e as Secretarias de Educação dos estados, do Distrito Federal e dos municípios que aderiram ao Plano de Ações Articuladas (PAR), tendo em vista a meta nacional estabelecida no Plano Nacional de Educação (PNE) de alfabetizar todas as crianças até, no máximo, 8 anos de idade.

\footnotetext{
2 De acordo com o documento orientador do programa divulgado em 2017, a estrutura da formação sofreu alterações em relação a que deu base para o desenvolvimento do programa até 2016 (BRASIL, 2017).
} 
No interior dessas instâncias, conjugou-se o envolvimento de diferentes atores os quais, em articulação, desenvolveram a formação dos orientadores de estudo (OEs) e dos professores alfabetizadores (PAs). Configurou-se como o maior programa de formação implementado no Brasil a fim de apoiar todos os professores que atuavam como alfabetizadores visando melhorias em suas intervenções e, portanto, potencializar as condições de aprendizagem. Portanto, anunciou-se como uma iniciativa para potencializar a melhoria da prática docente na busca por reverter a "[...] dura realidade de constatar que muitas crianças têm concluído sua escolarização sem estarem alfabetizadas" (BRASIL, 2015, p. 10).

Para o feito, trouxe a novidade de permitir que o professor com o crivo da experiência integrasse a universidade como formador, o PNAIC carregou a possibilidade de representar inovação. Dito isso, importante esclarecer que em certa medida, o programa contemplou as indicações de pesquisadores, como Infantino (2015); Butlein (2015); Altet et al. (2003); Silva Júnior (2015) e Mizukami (2006), os quais, guardadas as diferenças, consideram que o formador deva ser portador de uma sólida vivência como professor dos anos iniciais, qualificado e muito envolvido nos processos de ensino e aprendizagem. Em comum, defendem que essa é uma condição para se deslocar a ideia de saber acadêmico como soberano ao saber produzido no fazer pedagógico, estabelecendo uma relação horizontal entre eles. Sendo assim, o PNAIC teve a possibilidade de redefinir o modelo tradicional de formação.

Nesse contexto foi realizado o estudo de doutorado intitulado "O professor formador no PNAIC: formação, experiência e atuação" o qual objetivou entender quem foi o professor formador que atuou no PNAIC desde sua implementação pela UFJF até o ano de 2016. De modo mais específico, buscou-se entender aspectos voltados para as trajetórias formativas dos formadores, suas qualificações, o processo que os constituiu formadores, os saberes que julgam elementares e as percepções da rede formativa instituída pelo PNAIC. Em especial, buscou-se ainda entender se perceberam possível relação entre seu papel e a possibilidade de integrar as instâncias formativas universidade-escola. São os dados desse estudo que alimentarão este texto.

Considerando o objetivo de entender o papel do professor formador no âmbito do PNAIC, especificamente, no polo constituído pela UFJF, entendeu-se que a base do trabalho seria interpretativa, tendo como referência as inferências realizadas a partir dos dados coletados. Em virtude disso, optou-se pelo desenvolvimento de uma pesquisa de caráter qualitativo, a qual viabilizaria a produção dos dados com base nas reflexões do pesquisador como parte do processo de produção de conhecimentos (FLICK, 2009). A partir dessa escolha metodológica, definiu-se, como instrumentos para a obtenção e para a análise dos dados, o levantamento bibliográfico sobre a temática Formação de Professores, a análise documental sobre o PNAIC e entrevistas semiestruturadas com os agentes formativos que atuaram na UFJF. 
Desse modo, após a proposta de estudo ser encaminhada para avaliação e ser aprovada ${ }^{3}$ pelo Comitê de Ética em Pesquisa com Seres Humanos (CEP) da UFJF, os dados que fundamentaram o trabalho foram construídos a partir da preocupação inicial de situar o formador no âmbito do processo formativo para o exercício da docência nos anos iniciais e, assim, ampliar o conhecimento sobre o contexto da formação docente no Brasil. Para tanto, deu-se início ao levantamento bibliográfico sobre o campo formativo realizado em 10 (dez) periódicos ${ }^{4}$ da área, que possuem Qualis/Capes A1, de acordo com a listagem divulgada em 2015, selecionados em função de sua importância no campo da educação brasileira; e, ainda, na produção da Revista Educação em Foco, escolhida por ser uma publicação da instituição em que se situava o Programa de Pós-Graduação, no qual foi desenvolvida a pesquisa, e por ser o polo do PNAIC do estudo em questão. Essa atividade foi o ponto de partida na busca de entender e fundamentar o campo que abrigou a questão de estudo e acompanhou todo o desenvolvimento da pesquisa. Além desses periódicos, no propósito de ter um conhecimento mais sistemático sobre o formador de professores, recorreu-se à leitura de publicações organizadas em livros e eventos reconhecidos no campo da formação de professores. Conjugou-se, ainda, ao universo de construção de conhecimentos, com enfoque no formador, o levantamento de publicações sobre o PNAIC com o objetivo de melhor apreender o programa que abriga os sujeitos da pesquisa.

Tendo em vista ampliar a discussão, especificamente em relação ao PNAIC, realizou-se, também, uma análise documental no âmbito dos textos oficiais e das prescrições legais que instituíram o programa, dentre os quais destacaram-se leis, pareceres, decretos e os Cadernos de Formação orientadores da proposta. A partir da leitura desses documentos, foi-se construindo um corpus com o propósito de se ter uma amostra representativa de como a formação era apresentada nos documentos, de seus objetivos, qual o discurso que atravessava a proposta, enfim, com a finalidade de desenhar a proposta à luz de suas prescrições legais. Como caminho geral para a construção dessa amostra, foi feita, inicialmente, uma busca no site do MEC dos documentos sobre o programa e, em especial, sobre o eixo da formação. Os documentos encontrados foram lidos na íntegra. Junto à leitura, foi anotado os pontos os quais se acreditava que poderiam auxiliar tanto no entendimento do objetivo quanto na intencionalidade da implementação da referida política de formação. A partir dessas anotações, foram realizadas análises dos padrões e contrastes dos significados visíveis e, assim, foi possível construir a contextualização do programa de formação.

Somou-se a esses instrumentos a realização de entrevistas semiestruturadas a partir de um roteiro com questões norteadoras, com 30 (trinta) dos 33 (trinta e três) formadores que ao longo de

\footnotetext{
${ }^{3}$ Conforme número do parecer: 1.715.141.

${ }^{4}$ Cadernos de Pesquisa; Educação e Realidade; Cadernos Cedes; Educação \& Sociedade; Educar em Revista; Revista Brasileira de Educação; Educação e Pesquisa; Educação em Revista; Avaliação; Revista Ensaio; Revista Educação em Foco.
} 
2012 a 2016 atuaram junto a UFJF. A adoção desse procedimento metodológico se justificou pelo reconhecimento do rico potencial de produção de linguagem, marcada pela dimensão social, em que o entrevistador e entrevistado interagem verbalmente, construindo conhecimentos sobre o fenômeno estudado (LÜDKE; ANDRÉ, 1996).

Além dos formadores, a coordenadora geral, 2 (dois) coordenadores adjuntos do PNAIC pela UFJF e uma Secretária de Educação de um dos municípios atendidos pelo polo da UFJF também foram entrevistados. Pretendeu-se, com essa estratégia, entender a expectativa desse grupo de profissionais envolvidos nessa formação em relação à atuação dos outros formadores do grupo, no caso, os que atuaram diretamente com os OEs. Interessou entender, ainda, quem eram esses formadores, como foram recrutados, como lhes foi garantida a formação para atuarem como formadores, como se constituíram formadores de professores, o que fizeram efetivamente na formação do PNAIC, como conceberam suas funções e, também, suas opiniões acerca de uma possível relação entre o papel do formador e a sua possibilidade de viabilizar a integração entre universidade e escola. Sabendo que a equipe de coordenação teve relação direta com a seleção e organização dos momentos de formação entre os formadores e os OEs, suspeitou-se que tinham muito a dizer, justificando-se, assim, a aproximação com os membros que a compunham.

Todas as entrevistas realizadas receberam um tratamento comum à pesquisa qualitativa: após transcrita a gravação, foram impressas, lidas em um primeiro momento em um padrão de "leitura flutuante $^{5 \prime}$ para, posteriormente, serem retomadas e estudadas atenciosamente. A partir das propostas de análise de conteúdo de Bardin (2009), a qual se pauta em procedimentos clássicos, foram realizadas a análise do material textual e construção de quadros, a partir da utilização de categorias estabelecidas com base no modelo processual de análise do texto. Destaca-se que os primeiros quadros foram construídos para registrar as falas de cada um dos formadores. A partir dessas falas organizadas em quadros, foi-se percebendo indicadores que viabilizaram o desmembramento em unidades menores, as quais foram classificadas a partir de elementos de significação e reagrupadas em categorias. Para cada categoria, criou-se um quadro de análise. Para esse estudo, totalizaram 5 (cinco) grandes quadros: perfil dos formadores entrevistados, contato inicial dos formadores no PNAIC, o trabalho do formador no PNAIC, avaliação do formador sobre o PNAIC, limites e possibilidades do PNAIC. Por meio destes, tornou-se viável fazer cruzamentos dos aspectos que se sobressaíam, que se relacionavam e, de modo contrário, os que não se relacionavam, favorecendo captar as percepções das pessoas entrevistadas. Nesse sentido, possibilitaram a aproximação com os formadores para além das aparências, observando-se as recorrências e as contradições constitutivas dos sujeitos

\footnotetext{
${ }^{5}$ De acordo com Bardin (2009, p. 68), diz respeito a uma leitura geral do texto para ter ciência do todo. Seria "uma primeira leitura, a qual podem surgir intuições que podem ser formuladas em hipóteses".
} 
pesquisados. Enfim, foi possível ter uma visão geral do professor formador no PNAIC. O trabalho de análise das entrevistas foi ampliado quando cotejado com os estudos acadêmicos e com os aspectos legais norteadores do PNAIC.

Interessante mencionar que à medida que se foi realizando o tratamento dos dados, novas questões se revelaram, demandando a realização de outros momentos de entrevistas. Desse modo, tendo em vista a preocupação com a consistência dos dados produzidos, o número total de entrevistas - planejado inicialmente em 33 (trinta e três), considerando 30 formadores, a coordenadora geral e os 2 (dois) coordenadores adjuntos - foi alterado para 40 (quarenta) devido à necessidade de retornar o diálogo e incluir uma Secretária de Educação de um município que integrou o polo formativo, por ter sido esse município indicado por alguns dos formadores entrevistados e pela coordenadora geral como uma referência no processo de construção de uma formação de rede.

Em um primeiro momento, as entrevistas foram pensadas para serem realizadas pelo contato face a face. Desse modo, após o aceite dos participantes, foi agendado um horário e escolhido um local com prioridade de atendimento às demandas dos entrevistados. No entanto, devido à distância física, por morarem em outras cidades, outra estratégia teve que ser tomada. Desse modo, com 3 formadores residentes em Lavras, Três Rios e Barbacena, respectivamente, combinou-se que as entrevistas, após pré-agendadas, aconteceriam usando o suporte da tecnologia do Skype ${ }^{6}$. Contudo, com dois deles isso não foi possível por problemas técnicos não solucionados pelos usuários que pretendiam a interlocução. Nesse caso, as entrevistas realizaram-se utilizando a tecnologia do WhatsApp ${ }^{7} .0$ sucesso desse recurso como uma forma para a realização das entrevistas fez com que esse procedimento fosse adotado, também, para a interlocução com outras duas formadoras que, embora residissem em Juiz de Fora, demonstraram dificuldade de encontro presencial. Assim, após algumas tentativas de contato face a face sem êxito, realizou-se, com essas duas formadoras, a entrevista via WhatsApp. Outro fato a se considerar foi o de que uma formadora, ao responder positivamente o aceite para compor o grupo que auxiliaria na produção de dados deste estudo, pediu que lhe fosse encaminhado o roteiro antes do encontro marcado para a realização da entrevista. Com essa formadora houve, também, demonstração de dificuldade de tempo para o encontro. Após várias tentativas sem sucesso, ela justificou, por meio de um e-mail, que estava muito atarefada, mas que gostaria muito de contribuir com o estudo. No mesmo e-mail, ela anexou um arquivo relatando sua vivência como formadora. Percebi que, nesse relato, a formadora usou o roteiro que eu the havia encaminhado diante da solicitação feita anteriormente. Esse tipo de retorno pode ser um exemplo do posicionamento de Flick (2009) sobre o receio de algumas pessoas participarem de entrevistas realizadas pessoalmente. Para

\footnotetext{
6 Trata-se de um software que permite comunicação pela Internet através de conexões de voz e vídeo.

${ }^{7}$ Consiste em um aplicativo de mensagens instantâneas e chamadas de voz e vídeo para smartphones.
} 
ele, "pode haver algumas pessoas que se sintam apreensivas para responder espontaneamente a uma série de perguntas durante mais de uma ou duas horas, o que pode levá-las a recusar participação na pesquisa" (FLICK, 2009, p. 240). Portanto, a condução de entrevistas por meio de recursos tecnológicos se apresentou como uma opção mesmo sem um planejamento prévio. Entretanto, cabe destacar que para Flick (2009):

\begin{abstract}
Muitos dos métodos qualitativos existentes vêm sendo transferidos e adaptados às pesquisas que utilizam a internet como ferramenta, como fonte ou como questão e pesquisa. Âmbitos novos com as entrevistadas por e-mail, ou grupos focais on line e a etnografia virtual levantam questões de pesquisa relativas à ética e aos problemas práticos (p. 32).
\end{abstract}

Considerando essa argumentação, buscou-se priorizar as entrevistas presenciais. Sendo assim, com exceção dos casos mencionados anteriormente, com todos os outros 24 (vinte e quatro) formadores a entrevista realizou-se com presença física do entrevistador e entrevistado. Também foi assim que aconteceram as entrevistas com os 3 coordenadores e com a Secretária de Educação.

A abordagem com todos os entrevistados foi a mesma: explicava-se o objetivo da pesquisa, dava-se uma ideia geral das questões a serem tratadas, informava-se sobre o tempo aproximado de duração e se pedia a autorização para que a "conversa" fosse gravada, a fim de que fossem transcritas em um momento posterior. Desse modo, cada entrevista, realizada com aproximadamente uma hora e vinte de conversa com os sujeitos participantes, foi gravada e, posteriormente, transcrita para ser analisada. Esclareceu-se, ainda, nesse contato inicial com os sujeitos participantes, que, por meio do áudio, seria feita a transcrição e esta seria encaminhada a cada um dos participantes para uma revisão. Ademais, deixou-se claro que, juntamente com a transcrição, seriam encaminhados, a fim de serem assinados, os termos de consentimento exigidos pelo CEP, firmando a autorização para uso dos dados. Por fim, informou-se que os dados pessoais seriam preservados para evitar a exposição e constrangimento ao entrevistado. Importante esclarecer, nesse momento, que os nomes usados ao longo da pesquisa são fictícios, procedimento que não se aplica ao coordenador adjunto de Matemática, o qual autorizou o uso do seu próprio nome, e, também, não foi garantido à coordenadora geral do programa, por ser apenas uma pessoa nessa função, o que torna possível sua identificação.

Vale ressaltar, ainda, que havia a expectativa de que o estudo contasse ainda com dados construídos a partir da observação dos encontros da coordenação e dos formadores, realizados com o objetivo de prepararem a formação oferecida ao município. Pretendia-se, inclusive, observar os momentos de formação presencial. A opção em realizar a observação como mais um procedimento metodológico teve como justificativa o acompanhamento in loco das vivências dos formadores. 
Acredita-se que isso ampliaria ainda mais a discussão sobre o estudo. No entanto, em virtude da alteração do formato original do programa em 2017, conforme a Portaria n. 826 (BRASIL, 2017), a observação não foi realizada. Contudo, esse fato não acarretou maiores problemas para a realização da pesquisa, visto que o objetivo central do estudo se caracterizou por um cunho explicativo, a partir da ótica dos formadores, e que, pelos procedimentos adotados, foi possível de ser realizada.

3 Algumas ponderações sobre os desafios do estudo da política de formação instituída pelo PNAIC

Como já mencionado, embora a formação de professores receba destaque no âmbito dos projetos que preconizam melhoria da qualidade da educação (GATTI; BARRETO; ANDRÉ, 2011), no campo acadêmico, ainda se percebe um baixo número de estudos sobre políticas de formação docente (ANDRÉ, 2013). Frente a isso, o trabalho enfrentou alguns desafios no que se refere ao estudo de uma política de formação de professores, o que implicou na dificuldade teórica de contato com uma literatura que auxiliasse de uma maneira mais ampla na construção do referencial teórico e na discussão dos dados produzidos.

Além disso, no universo dos estudos sobre o PNAIC, a pesquisa enfrentou o desafio de tratar de um programa que abrigava muitas críticas no cenário nacional. A realidade era de um campo com poucos trabalhos dedicados a pesquisas empíricas tendo como maior parte, publicações que se dedicavam a analisar o texto legal, à luz de um projeto gerencialista de educação, cujos princípios pautavam-se, sobretudo, no desmantelamento da educação pública e na maximização da atuação reguladora do Estado (FRANGELLA, 2016; DICKEL, 2016; LUZ; FERREIRA, 2013; BASSOUTO, 2013; ESQUINSANI, 2016). Com efeito, muitos dos estudos publicados no momento da realização do estudo em questão relacionavam as ações formativas do PNAIC a um processo que buscava alinhar a formação a um processo de fortalecimento de práticas de controle e monitoramento, reforçando um processo de culpabilização das redes de ensino e, em especial, dos professores, pela situação de aprendizagem dos alunos. $O$ entendimento de grande parte dos estudos sobre o PNAIC relaciona a proposição de Direitos de Aprendizagem a um mecanismo pautado na concepção de competência. Nesse entendimento, relacionam a formação pelo PNAIC ao objetivo central de adequar a formação de professores às exigências legais postas para a educação básica e aos sistemas de avaliação em desenvolvimento (FREITAS, 2012). Em geral, percebia-se que o entendimento no campo acadêmico parecia seguir uma tendência internacional de atribuir a essa política educacional o entendimento de ser mais uma formação delineada para desqualificar o fazer docente, "ditando" aos professores os saberes e modos de agir enquanto alfabetizadores. As críticas feitas ao programa por parte significativa da comunidade acadêmica recaíam no entendimento do PNAIC como mais uma formação orientada por um modelo de formação em cascata, no qual um primeiro grupo de profissionais é capacitado para organizar e repassar o conteúdo formativo, assumindo a função de capacitador de um novo grupo 
(GATTI; BARRETO, 2009), fortalecendo assim, o caráter prescritivo que negligencia o saber do professor em formação. A despeito, esses entendimentos foram compreendidos, porém refutados pelos formadores. Desse modo, embora tenham sido dados não desprezados por eles, não foram tratados como aspectos centrais do programa a partir de seus entendimentos. Ao contrário, para eles a proposta formativa em questão, a partir do esforço que empreenderam, propiciou a reflexão sobre o fazer pedagógico dos PAs a partir do diálogo com os OEs. Em geral, afirmaram que assim, a formação reverberou em práticas a serviço dos professores e em benefício dos estudantes, fortalecendo, inclusive, o fazer docente.

Interessante destacar ainda que o grupo entrevistado afirmou que suas ações deveriam e poderiam ter sido potencializadas a partir de uma movimentação nas redes de ensino. Sobre isso, tinham como expectativa que a partir da interlocução com os OEs, o programa fomentasse a formação de rede, ou seja, uma formação organizada pelos sistemas de ensino de cada localidade oportunizando a participação de todos os professores. Além disso, entendiam que essa formação deveria ter como referência as demandas por eles apresentadas, tendo em vista o desenvolvimento do processo de ensino-aprendizagem. Por tudo, o contexto favorável que os formadores percebiam a respeito das possibilidades formativas instituídas pelo PNAIC demandava, segundo a ótica deles, o envolvimento das partes que constituíam a rede de formação. Nessa percepção, o rompimento de um elo da rede afetava toda a estrutura da proposta, trazendo prejuízos à implementação do programa. Sobre isso apontaram fragilidades de cada instância da rede que organizava o programa frente as suas responsabilidades assumidas no ato da pactuação (MACHADO, 2018).

Contudo, em meio aos desafios, o estudo revelou a importância de pesquisas que deem voz aos atores envolvidos no processo de implementação de uma política. No caso específico, foi possível perceber que por mais que uma política pareça ter sido construída de "cima para baixo", os sujeitos que com ela atuam podem buscar agirem sincronicamente e alterarem suas possibilidades. Desse modo, é preciso considerar que "o contexto da prática é onde a política está sujeita à interpretação e recriação e onde a política produz efeitos e consequências que podem representar mudanças e transformações significativas na política original” (MAINARDES, 2006, p. 53). No caso específico do PNAIC, os dados sinalizaram que, ao interpretarem, traduzirem, reconstruírem e recriarem o programa em relação ao contexto, os formadores recontextualizaram a proposta formativa. Em linhas gerais, foi possível observar um processo marcado por uma predisposição comum de buscar a "zona de escape" aos ditames legais e, portanto, delineado por possibilidades de deslizamentos de alguns preceitos atravessadores da política central que pudessem remetê-la a lógica gerencialista de educação como era a preocupação de muitos pesquisadores diante do cenário das atuais políticas educacionais (FREITAS, 2012; DICKEL, 2016; LUZ, 2013, 2017; ROCHA et al. 2014). 
Por fim, mais não menos importante, acerca da compreensão dos entrevistados sobre a percepção dos formadores quanto a oportunidade de por meio deles, no interior do programa, integrar universidade e Escola, parece ter sido consenso o entendimento de que o crivo da experiência favoreceu a possibilidade de se alterar o modelo comumente praticado no processo formativo, impactando um movimento de parceria entre essas duas instituições de ensino. Nesses termos, podese afirmar que tendo o programa se consubstanciado como um elemento importante para descontruir a disputa em espaços hierarquicamente demarcados, criou um caminho para o diálogo entre a pesquisa acadêmica e a escola, situação tão esperada pelos estudiosos do campo da formação docente (GATTI, BARRETO, ANDRÉ, NÓVOA, CÁNARIO, VAILLANT). No contexto dessa dinâmica, os formadores se reconheceram como figuras centrais. Afirmaram perceber que, por meio dos embates que sustentaram, criaram possibilidades para que a formação tivesse um desenho pautado na praxiologia (GATTI, 2013).

\section{Breves considerações}

O objetivo percorrido ao longo deste artigo foi o de dar visibilidade à trajetória de uma pesquisa realizada a partir de uma política de formação docente tendo em vista fomentar contribuições para esse campo de estudo. Frente aos desafios desvelou-se como fundamental dar voz aos atores envolvidos na implementação de uma política, tendo em vista seu poder de condução e, em consequência, a possibilidade de influenciar seus resultados (MAINARDES, 2006). Desse modo, os dados corroboram com estudos, tais como os realizados pelo sociólogo inglês Stephen Ball e colaboradores, como Bowe, apresentados no Brasil por pesquisadores como Mainardes (2006), sobre ciclo de políticas. Assim, superado o desafio inicial de trazer à discussão uma política até então valorada de forma negativa por grande parte dos estudos acadêmicos, analisando-a a partir do olhar dos formadores para além de suas características gerencialistas, se desvelou a possibilidade de entende-la como um processo de reconstrução e reorganização de estratégias para a realização de um trabalho. Nesse caso, diante do objetivo de estudo em questão, foi possível perceber as possibilidades de conduzir uma proposta de modo a modificar possíveis interesses do discurso oficial em um discurso mais próximo da realidade das escolas com base no preceito de potencializar a melhoria das práticas pedagógicas.

Nesses termos, os atores envolvidos em sua implementação prestaram uma grande contribuição para o entendimento do ciclo de uma política, sobretudo, no que se refere ao campo de atuação, revelando que, ao implementar uma política, esta não se realiza por completo da forma como foi o planejamento. Nesse sentido, evidenciam que uma "política é um processo social, um processo relacional, um processo temporal, discursivo" (BALL, 2015, p. 21). Essa dimensão nos leva a entender 
que política tem vida a partir dos sujeitos sociais que a ressignificam. Por isso, sua implementação diz respeito a uma versão local e particular de um movimento.

Pode-se concluir, em consonância com Freire (1997), que os formadores evidenciaram que a experiência histórica de estar no mundo, de intervir no mundo pode fazer uma situação melhorar. Afinal, conforme demonstrado pelo grupo, nossa "presença no mundo não é a de quem a ele se adapta mas a de quem nele se insere. É a posição de quem luta para não ser apenas objeto mas sujeito também da história" (FREIRE, 1997, p. 60).

Referências

ALTET, Marguerite; PERRENOUD, Phillipe; PAQUAY, Leopol (org.). A Profissionalização dos Formadores de Professores. Trad. Fátima Murad. Porto Alegre : Artmed, 2003.

ANDRÉ, Marli. Práticas Inovadoras na Formação de Professores. Campinas, SP: Papirus, 2013.

BALL, Stephen J. [2015]. Olhares. Guarulhos, v. 3, n. 2, p. 161-171. Entrevista concedida a MAINARDES, Jefferson. Tradução de Janete Bridon.

BARDIN, L. Análise de Conteúdo. Lisboa, Portugal; Edições 70, LDA, 2009.

BASSOUTO, Gisele Teixeira Chaves. O Programa Nacional pela Alfabetização na Idade Certa à luz do atual Estado da Arte sobre Alfabetização. Maringá. 2013. 27 f. Trabalho de Conclusão de Curso (Graduação em Pedagogia) - Universidade Estadual de Maringá, 2013.

BRASIL. Portaria no 867, de 4 de julho de 2012. Institui o Pacto Nacional pela Alfabetização na Idade Certa e as ações do Pacto e define suas diretrizes gerais. Diário oficial [da] República Federativa do Brasil, Poder Executivo, Brasília, DF, 5 jul 2012. Disponível em: < http://pacto.mec.gov.br/images/pdf/port_867_040712.pdf>. Acesso em: 20 ago. 2016.

. Secretaria de Educação Básica. Diretoria de Apoio à Gestão Educacional. Pacto nacional pela alfabetização na idade certa: formação de professores no pacto nacional pela alfabetização na idade certa. Caderno de Apresentação Brasília: MEC, 2012a.

. Secretaria de Educação Básica. Diretoria de Apoio à Gestão Educacional. Pacto nacional pela alfabetização na idade certa: formação de professores no pacto nacional pela alfabetização na idade certa. Caderno de Apresentação Brasília: MEC, 2015.

. Ministério da Educação. Portaria n. 826, de 7 de julho de 2017. Dispõe sobre o Pacto Nacional pela Alfabetização na Idade Certa - PNAIC e suas ações, diretrizes gerais e a ação de formação no âmbito do Programa Novo Mais Educação - PNME. Brasília, 7 de julho de 2017. Disponível em: http://www.lex.com.br/legis_27464570_PORTARIA_N_826_DE_7_DE_JULHO_DE_2017.aspx. Acesso em: 29 dez. 2017.

BUTLEN, Max. Os desafios da participação dos profissionais da escola na formação dos professores: um olhar sobre a experiência francesa de universitarização e profissionalização docente. In: Gatti, Bernadete Angelina, et. al. Por uma revolução no campo da formação de professores. 1. ed. São Paulo: Editora Unesp, 2015. 
CANDAU, Vera Maria (org.). Universidade e Formação de Professores: que rumos tomar? Magistério: construção cotidiana. Petrópolis, Rio de Janeiro: Vozes, 2003.

DICKEL, Adriana. A Avaliação Nacional da Alfabetização no Contexto do Sistema de Avaliação da Educação Básica e do Pacto Nacional pela Alfabetização na Idade Certa: responsabilização e controle. Cadernos Cedes, Campinas, v. 36, n. 99, p. 193-206, maio-ago., 2016.

DOURADO, Luiz Fernandes. A formação de professores e a base comum nacional: questões e proposições para o debate. Revista Brasileira de Política e Administração da Educação. V. 29, n. 2, p. 367-388. Mai/ago. 2015.

ESQUINSANI, Rosimar Serena Siqueira. O Pacto Nacional Pela Alfabetização na Idade Certa e a responsabilização (Accountability) do professor alfabetizador. Revista Ibero-Americana de Estudos em Educação. Araraquara, São Paulo, v. 11, n. esp. 4, p. 2465-2482, 2016. Disponível em: seer.fclar.unesp.br/iberoamericana/article/view/9203. Acesso em: 28 dez. 2017.

FLICK, Uwe. Uma Introdução à Pesquisa Qualitativa. Porto Alegre: Bookman. 2009.

FRANGELLA, Rita de Cássia Prazeres. Um Pacto Curricular: O Pacto Nacional pela Alfabetização na Idade Certa e o Desenho de uma Base Comum Nacional. Educação em Revista. Belo Horizonte, v.32, n.02, p. 69-89, abril/junho, 2016. Disponível em: http://www.scielo.br/pdf/edur/v32n2/1982-6621-edur-3202-00069.pdf. Acesso em: 19 dez. 2017.

FREIRE, P. Pedagogia da Autonomia: saberes necessários à prática educativa. São Paulo: Paz e Terra, 1997. (Coleção Leitura).

FREITAS, Luiz Carlos de. Os reformadores empresariais da educação: da desmoralização do magistério à destruição do sistema público de educação. Sociedade e educação. Campinas, v.33, n. 119, 2012.

GARCIA, C. M. A. Formação de professores: novas perspectivas baseadas na investigação sobre o pensamento do professor. In: NÓVOA, A. (Org.). Os professores e sua formação. Lisboa: Dom Quixote, 1999. p.51-76.

GATTI, B. A.; BARRETO, Elba de Sá, ANDRÉ, Marli. Políticas docentes no Brasil: um estado da arte. Brasília: UNESCO, 2011.

; BARRETO, Elba de Sá. (Coords.). Professores do Brasil: impasses e desafios. Brasília: UNESCO, 2009.

GATTI, B. A. Educação, escola e formação de professores: políticas e impasses. Educar em Revista. Curitiba, n. 50, p. 51-67. Out./dez. 2013.

. Formação de Professores: compreender e revolucionar. In: et. al. Por uma revolução no campo da formação de professores. 1. ed. São Paulo: Editora Unesp, 2015.

IMBERNÓN, F. Inovar o ensino e a aprendizagem na universidade. Tradução de Silvana Cobucci Leite. São Paulo: Cortez, 2011.

INFANTINO, Agnese. Qual formação no trabalho educativo com a primeira infância? Educação e Realidade. Porto Alegre, RS, v. 40, n. 4, p. 987-1004. Out./dez. 2015. 
LÜDKE, Menga; ANDRÉ, Marli E.D.A. Pesquisa em educação: abordagens qualitativas. São Paulo: EPU. 1996.

LUZ, Iza Cristina Prado da; FERREIRA, Diana Lemes. Pacto Nacional Pela Alfabetização Na Idade Certa: Formação, Avaliação e Trabalho Docente em Análise. Revista Brasileira de Políticas e Administração da Educação, v. 29, n. 3. Set./dez. 2013.

. Pacto Nacional da Alfabetização na Idade Certa (PNAIC): A Política de Formação Continuada de Professores e a Legislação Educacional em Análise. In: Encontro Brasileiro da Redestrado. Apresentação oral. 2017.

MAINARDES, Jefferson. Abordagem do Ciclo de Políticas: uma contribuição para a análise de políticas educacionais. Revista Educação e Sociedade, Campinas, n.94, p. 47-69, jan./abr. 2006.

MIZUKAMI, Maria da Graça Nicoletti. Aprendizagem da docência: professores formadores. Revista ECurriculum, v. 1, n.1. Dez./Jul. 2005-2006.

NÓVOA, António. A formação da profissão docente. In: NÓVOA, A. (Org.). Os professores e sua formação. Lisboa: Dom Quixote, 1995. p.15-53.

. Relação Escola-Sociedade: novas respostas para um velho problema. In: SERBINO et al. (Org.). Formação de Professores. São Paulo: Fundação Ed. UNESP, 1998. p.19-39.

ROCHA, Sônia Cláudia Barroso da; Bissoli, Michelle de Freitas; BOTELHO, Arminda Rachel de. Pacto Nacional pela Alfabetização na Idade Certa como uma Política de Formação Docente do Estado de Concepção Neoliberal. II Congresso Nacional de Formação de Professores. XII Congresso Estadual Paulista sobre Formação de Educadores. 2014. Disponível em: http://unesp.br/anaiscongressoeducadores/ArtigoVisualizar?nome_arquivo=http://200.145.6.217/pr oceedings_arquivos/ArtigosCongressoEducadores/703.pdf. Acesso em: 24 nov. 2017.

SCHÖN, D. A. Formar professores como profissionais reflexivos. In: NÓVOA, A. (Org.). Os professores e sua formação. Lisboa: Dom Quixote, p. 77-91. 1995.

SILVA JÚNIOR, Celestino Alves da. Construção de um espaço público de formação. In: GATTI, Bernardete Angelina (et. al.). Por uma revolução no campo da formação de professores. 1. ed. São Paulo: Editora Unesp, 2015. 